\title{
The Prevalence of Atrial Fibrillation among Acute Medical Admissions in Kuwait
}

\author{
Mustafa Ridha ${ }^{\mathrm{a}}$ Amin Al-Sayed Amin ${ }^{\mathrm{a}}$ Salhamoud A. Saleh ${ }^{\mathrm{a}}$ Boby Cherian ${ }^{\mathrm{a}}$ \\ Fawziah Al-Kandari ${ }^{\mathrm{b}}$ Faridah Redha $^{\mathrm{c}}$ Khalid Jamal ${ }^{\mathrm{a}}$ Zouheir Bitar $^{\mathrm{a}}$ \\ ${ }^{a}$ Department of Internal Medicine, Adan Hospital, ${ }^{b}$ Chest Diseases Hospital, and ${ }^{c}$ Farwania Hospital, \\ Ministry of Public Health, Kuwait
}

\section{Key Words}

Arrhythmia $\cdot$ Atrial fibrillation $\cdot$ Prevalence $\cdot$ Stroke

\begin{abstract}
Objective: To establish the prevalence of atrial fibrillation (AF) among acute medical admissions to the Adan Hospital, Kuwait, and to evaluate the clinical features of the patients. Subjects and Methods: Of 2,833 acute medical admissions to the Adan Hospital from January 1 to May $31,2003,120$ patients with AF were included in the study. The patients were divided into paroxysmal or persistent (PPAF), and chronic atrial fibrillation (CAF). The prevalence of stroke and clinical features of the CAF patients with and without strokes were studied. All the patients with $\mathrm{AF}$ underwent echocardiography to evaluate left ventricular ejection fraction (LVEF) and left atrial dimension (LAD). Results: The prevalence of AF in the study period was $4.24 \%$, of which $68.3 \%$ had CAF and $31.7 \%$ had PPAF. The prevalence of heart failure, ischemic heart disease, systemic hypertension, and diabetes mellitus was $27.5,55.8,65.8$, and $53.3 \%$, respectively. Patients with CAF were older and had a higher prevalence of heart failure compared to PPAF patients. Of the patients with CAF, $26.8 \%$ had at least one episode of stroke. The CAF patients had lower LVEF and larger LAD
\end{abstract}

than PPAF patients. Stroke patients with CAF had lower LVEF and larger LAD as compared to those without stroke. Conclusion: Atrial fibrillation is a common admission diagnosis in our hospital. Patients with AF commonly suffer from heart failure, hypertension, diabetes mellitus, and ischemic heart disease. There was a high prevalence of stroke among CAF patients.

Copyright (C) 2005 S. Karger AG, Basel

\section{Introduction}

Atrial fibrillation (AF) is the most common cardiac arrhythmia affecting over 2 million patients in the United States of America alone [1]. Much of the morbidity associated with $\mathrm{AF}$ is attributed to a 5- to 6-fold increase in the risk of stroke [2]. Pooled data from studies of chronic atrial fibrillation (CAF) in North America, the United Kingdom, and Iceland suggest a prevalence of $0.5-1 \%$ in the general population [2-6]. The objective of this study was to establish the prevalence of AF among the acute medical admissions in a busy general hospital, the Adan Hospital in Kuwait, and to evaluate the clinical features.

\section{KARGER}

Fax +41613061234

E-Mail karger@karger.ch

www.karger.com
(C) 2005 S. Karger AG, Basel

$1011-7571 / 05 / 0143-0136 \$ 22.00 / 0$

Accessible online at:

www.karger.com/mpp
Mustafa Ridha

Department of Internal Medicine, Adan Hospital, Ministry of Public Health PO Box 20567

13066 Safat (Kuwait)

Tel. +965 3943600, 9413750, Fax +965 3949505, E-Mail ridha3@hotmail.com 
Table 1. Clinical features of the patients with AF on admission

\begin{tabular}{lll}
\hline & & $\%$ \\
\hline Age, years (mean $\pm \mathrm{SD})$ & $63.6 \pm 14.1$ & \\
Female gender & 76 & 63 \\
Heart failure & 33 & 27.5 \\
IHD & 67 & 55.8 \\
Hypertension & 79 & 65.8 \\
DM & 64 & 53.3 \\
RHD & 9 & 7.5 \\
Previous stroke & 19 & 15.8 \\
Thyroid disease & 1 & 0.8 \\
COAD & 4 & 3.3 \\
\hline
\end{tabular}

IHD = Ischemic heart disease; $\mathrm{DM}=$ diabetes mellitus; COAD $=$ chronic obstructive airway disease RHD $=$ rheumatic heart disease. Note: Some patients had more than one condition.

Table 2. Comparison of patients with PPAF and CAF

\begin{tabular}{|c|c|c|c|}
\hline & $\begin{array}{l}\text { PPAF } \\
(\mathrm{n}=38)\end{array}$ & $\begin{array}{l}\text { CAF } \\
(n=82)\end{array}$ & $\mathrm{p}$ value \\
\hline Age, years $($ mean \pm SD) & $56.8 \pm 14.8$ & $66.8 \pm 14.5$ & $<0.001$ \\
\hline Female gender & $23 \quad(60.5 \%)$ & $53(64.6 \%)$ & NS \\
\hline Heart failure & $3(7.9 \%)$ & $30 \quad(36.6 \%)$ & $<0.001$ \\
\hline IHD & $17 \quad(44.7 \%)$ & $50 \quad(61 \%)$ & 0.12 \\
\hline Hypertension & $24 \quad(63.2 \%)$ & $55 \quad(67.1 \%)$ & NS \\
\hline DM & $18 \quad(47.4 \%)$ & $46 \quad(56.1 \%)$ & NS \\
\hline RHD & $1 \quad(2.6 \%)$ & $8 \quad(9.8 \%)$ & 0.27 \\
\hline Previous stroke & $2 \quad(5.3 \%)$ & $17 \quad(20.1 \%)$ & 0.03 \\
\hline Thyroid disease & 0 & $1 \quad(1.2 \%)$ & NS \\
\hline COAD & $2 \quad(5.3 \%)$ & $2(2.4 \%)$ & NS \\
\hline LVEF, \% & $52 \pm 15.5$ & $41.8 \pm 14.9$ & 0.002 \\
\hline $\mathrm{LAD}, \mathrm{cm}$ & $3.97 \pm 0.7$ & $4.24 \pm 0.83$ & 0.07 \\
\hline
\end{tabular}

IHD = Ischemic heart disease; $\mathrm{DM}=$ diabetes mellitus; $\mathrm{COAD}=$ chronic obstructive airway disease; $\mathrm{RHD}=$ rheumatic heart disease; $\mathrm{n}=$ number of patients.

\section{Patients and Methods}

The study population consisted of patients in whom AF was detected on the admission electrocardiogram among the patients admitted to the Medical Wards and Coronary Care Unit of the Adan Hospital, Kuwait, from January 1 to May 31, 2003. Using the guidelines for the management of patients with AF of the American College of Cardiology, American Heart Association and European Society of Cardiology [3], the patients were classified into two groups: (a) paroxysmal or persistent atrial fibrillation (PPAF) if the fibrillation spontaneously converted to sinus rhythm within 7 days or if persistent beyond 7 days and required electrical or chemical conversion, and (b) CAF if the episode was permanent and persisted over 1 year, a determination that was made from patients' history and medical records. The clinical features, hospital course, and echocardiographic findings of both groups were described and compared. M-mode echocardiography was performed by an experienced cardiologist, and left ventricular ejection fraction (LVEF) and left atrial dimension (LAD) were recorded. It was assumed that patients had ischemic heart disease if they met any of the following criteria: (1) a history of acute coronary syndrome, i.e. unstable angina, non-ST-elevation myocardial infarction, or ST-elevation myocardial infarction; (2) established coronary artery disease by coronary angiography, i.e. $>50 \%$ stenosis in at least one coronary artery; (3) anginal chest pain with stress-inducible ischemic evident through plain exercise stress test, stress echo or stress thallium-201 chloride scintigraphy, and (4) previous coronary artery bypass surgery or percutaneous coronary intervention.

\section{Statistical Analysis}

Quantitative data (LVEF and LAD) were recorded as means \pm $\mathrm{SD}$, and were compared using the paired two-tailed Student $t$ test. Qualitative (categorical) data were compared using Fisher's exact test. A probability level of $<0.05$ was considered statistically significant.

\section{Results}

The prevalence rate of patients with $\mathrm{AF}$ on admission was $4.24 \%$. Of these, 38 had PPAF (31.7\%) and $82 \mathrm{CAF}$ (68.3\%). Of the 38 with PPAF, 24 (63.0\%) had persistent $\mathrm{AF}$ that required either chemical or electrical cardioversion. The baseline features of the AF patients are shown in table 1 . The mean age of AF patients was $63.6 \pm 14.1$ years, and 76 were female and 44 male. There was a high incidence of heart failure (27.5\%); ischemic heart disease (55.8\%); systemic hypertension (65.8\%), and diabetes mellitus (53.3\%) among patients with AF. Moreover, $15.8 \%$ of AF patients had a previous history of stroke (not including this admission). Rheumatic heart disease (7.5\%) and thyroid disease $(0.8 \%)$ were not as common as the other comorbid conditions in these patients with AF. The clinical features and conditions of patients with PPAF and CAF are compared in table 2.

Patients with CAF were approximately 10 years older than those with PPAF. There were more patients with heart failure and a history of stroke in the CAF group as compared to the PPAF group ( $<<0.001$ and $p=0.03$, respectively). Compared to patients with PPAF, there was a trend toward a higher incidence (although statistically not significant) of ischemic heart disease, hypertension, diabetes mellitus, rheumatic heart disease, and thyroid disease in patients with $\mathrm{CAF}(61,67.1,56.1,9.8$, and $1.2 \%$, respectively). Moreover, the overall hospital stay in 
Table 3. Causes for admission

\begin{tabular}{lccl}
\hline & \multicolumn{2}{l}{ Patients } & p value \\
\cline { 2 - 3 } & PPAF $(\mathrm{n}=38)$ & $\mathrm{CAF}(\mathrm{n}=82)$ & \\
\hline Acute stroke & 0 & $13(15.9 \%)$ & $<0.01$ \\
Heart failure & $6(15.7 \%)$ & $36(43.9 \%)$ & $<0.01$ \\
RVR & $38(100 \%)$ & $64(78 \%)$ & $<0.0007$ \\
ACS & $3(7.9 \%)$ & $9(11 \%)$ & $<\mathrm{NS}$ \\
Sepsis & $2(5.3 \%)$ & $12(14.6 \%)$ & $<0.22$ \\
Other & $2(5.3 \%)$ & $18(22 \%)$ & $<0.03$ \\
\hline
\end{tabular}
drome.

RVR = Rapid ventricular rate; ACS = acute coronary syn-

Table 4. Features of CAF patients with/without stroke

\begin{tabular}{|c|c|c|c|}
\hline & $\begin{array}{l}\text { Stroke } \\
(n=22)\end{array}$ & $\begin{array}{l}\text { No stroke } \\
(\mathrm{n}=60)\end{array}$ & $\mathrm{p}$ value \\
\hline Age, years (mean $\pm S D)$ & $73.6 \pm 10.8$ & $64.8 \pm 15.6$ & $<0.001$ \\
\hline Female gender & $15 \quad(68.2 \%)$ & $39 \quad(65 \%)$ & NS \\
\hline $\mathrm{LAD}, \mathrm{cm}$ & $4.76 \pm 0.47$ & $4.07 \pm 0.85$ & $<0.001$ \\
\hline LVEF, \% & $34.55 \pm 13.3$ & $44.0 \pm 14.8$ & $<0.001$ \\
\hline Heart failure & $13 \quad(59.1 \%)$ & $17 \quad(28.3 \%)$ & 0.02 \\
\hline IHD & $(77.3 \%)$ & $33 \quad(55 \%)$ & 0.08 \\
\hline Hypertension & $18 \quad(81.1 \%)$ & $37 \quad(61.7 \%)$ & 0.14 \\
\hline $\mathrm{DM}$ & $(68.2 \%)$ & $31 \quad(51.7 \%)$ & 0.21 \\
\hline RHD & $(18.2 \%)$ & $4 \quad(6.7 \%)$ & 0.2 \\
\hline Hyperlipidemia & $6 \quad(27.3 \%)$ & $5 \quad(8.3 \%)$ & 0.06 \\
\hline
\end{tabular}

IHD = Ischemic heart disease; $\mathrm{DM}=$ diabetes mellitus; $\mathrm{RHD}=$ rheumatic heart disease.

patients with CAF was significantly longer than in patients with PPAF $(5.6 \pm 3.85$ vs. $3.8 \pm 2.94$ days, $\mathrm{p}<$ 0.005). Patients with CAF had significantly lower LVEF than those with PPAF (41.8 vs. $52 \%, \mathrm{p}=0.002)$. The LAD was higher in the CAF patients $(4.24$ vs. $3.97 \mathrm{~cm})$ even though the difference was statistically not significant $(\mathrm{p}=$ 0.07; table 2).

A greater proportion of patients with CAF had acute stroke or decompensated heart failure as a cause of their admission during their hospitalization when compared to those admitted with PPAF (15.9 vs. $0 \%, \mathrm{p}<0.01$, and 43.9 vs. $15.7 \%, \mathrm{p}<0.01$; table 3 ). CAF patients had a higher overall prevalence of stroke (old and new). Of the 82 patients with CAF, $22(26.8 \%)$ had a stroke. Table 4 summarizes the features of CAF patients who had a stroke compared to those who did not have a stroke. Patients with a history of stroke were older (73.6 vs. 64.8 years, $\mathrm{p}<0.001$ ), and had a higher prevalence of heart failure (59.1 vs. $28.3 \%, p=0.02)$. The patients with stroke had a higher prevalence of hypertension, ischemic heart disease, rheumatic disease, and hyperlipidemia compared to those who did not have a stroke, although the differences were not statistically significant. The LVEF was significantly lower, and the LAD was higher in the CAF who had stroke as compared to those who did not have stroke ( 34.55 vs. $44 \%, p<0.001$, and 4.7 vs. $4.07 \mathrm{~cm}, \mathrm{p}<0.001$, respectively).

\section{Discussion}

This is the first study in Kuwait to examine the prevalence of AF among acute medical admissions in a busy general hospital, the Adan Hospital. The prevalence of $\mathrm{AF}(4.24 \%)$ was higher than in a previously reported study conducted in Kuala Lumpur, Malaysia, which was $2.8 \%$ [7]. A possible explanation could be the fact that our study was over a period of 5 months, while that of Malaysia was only 1 month. Another possible explanation could be the influence of seasonal variation on the admission rate in which $\mathrm{AF}$ has been reported to have a peak during the winter period [8], as in our study that covered January to May. Moreover, the medical morbidities noted in this study were higher compared to other studies. The prevalence of comorbidities (table 1) was higher than that obtained from the National Hospital Discharge Survey in the United States from 1985 to 1999 [9]. It was noted in our study that more females had AF (63\%) compared to other studies [10]. In the Framingham Heart Study from 1987 to 1989 , the prevalence of AF in patients 65-84 years of age was higher in male than female patients [10]. This descriptive study shows that the prevalence of PPAF was significantly lower than that of CAF among the acute medical admissions. This could be due to the fact that most recent onset AF usually terminate spontaneously even prior to seeking medical attention [3]. Moreover, CAF patients had more medical comorbidities like heart failure decompensations and stroke, which almost always needed medical attention. The stroke patients in this study have a risk profile similar to other studies [11-17]. 


\section{Conclusion}

$\mathrm{AF}$ is a common diagnosis on admission to the Adan Hospital, Kuwait. More patients had the diagnosis of CAF as compared to PPAF.

\section{Acknowledgment}

We would like to thank Dr. Amin Marafie, Chairman of the Department of Medicine, Adan Hospital, for his continued help and guidance without whom this and other studies would not have been performed successfully.

\section{References}

$\checkmark 1$ Feinberg WM, Blackshear JL, Laupacis A, Kronmal R, Hart RG: The prevalence, age distribution, and gender of patients with atrial fibrillation. Analysis and implications. Arch Intern Med 1995;155:469-473.

$\checkmark 2$ Wolf PA, Dawber TR, Thomas HE Jr, Kannel WB: Epidemiologic assessment of chronic atrial fibrillation and risk of stroke: The Framingham study. Neurology 1978;28:973-977.

-3 Fuster V, Ryden LE, Asinger RW, Cannom DS, Crijns HJ, Frye RL, Halperin JL, Kay GN, Klein WW, Levy S, McNamara RL, Prystowsky EN, Wann LS, Wyse DG: ACC/AHA/ ESC guidelines for the management of patients with atrial fibrillation: Executive summary a report of the American College of Cardiology/ American Heart Association task force on practice guidelines and the European Society of Cardiology Committee for practice guidelines and policy conference (Committee to develop guidelines for the management of patients with atrial fibrillation) developed in collaboration with North American Society of Pacing and Electrophysiology. Circulation 2001; 104:2118- 2150 .

$\checkmark 4$ Flegel KM, Shipley MJ, Rose G: Risk of stroke in nonrheumatic atrial fibrillation. Lancet 1987;i:526-529.

$\checkmark 5$ Vaidya PN, Bhosley PN, Rao DB, Luisada AA: Tachyarrhythmias in old age. J Am Geriatr Soc 1976;24:412-414.
-6 Ostrander LD Jr, Brandt RL, Kjelsberg MO, Epstein FH: Electrocardiographic findings among the adult population of a total natural community, Tecumseh, Michigan. Circulation 1965;31:888-898.

-7 Freestone B, Rajaratnam R, Hussain N, Lip GY: Admissions with atrial fibrillation in a multiracial population in Kuala Lumpur, Malaysia. Int J Cardiol 2003;91:233-238.

-8 Frost L, Johnsen SP, Pedersen L, Husted S, Engholm G, Sorensen H, Rothman KJ: Seasonal variation in hospital discharge diagnosis of atrial fibrillation: A population-based study. Epidemiology 2002;13:211-215.

$>9$ Wattigney WA, Mensah GA, Croft JB: Increasing trends in hospitalization for atrial fibrillation in the United States, 1985 through 1999: Implication for primary prevention. Circulation 2003;108:711-716.

10 Wolf PA, Benjamin EJ, Belanger AJ, Kannel WB, Levy D, D'Agostino RB: Secular trends in the prevalence of atrial fibrillation: The Framingham Study. Am Heart J 1996;131:790795.

11 Risk factors for stroke and efficacy of antithrombotic therapy in atrial fibrillation. Analysis of pooled data from five randomized controlled trials. Arch Intern Med 1994;154: 1449-1457.
2 Hart RG, Halperin JL: Atrial fibrillation and thromboembolism: A decade of progress in stroke prevention. Ann Intern Med 1999;131: 688-695.

13 Wang TJ, Massaro JM, Levy D, Vasan RS, Wolf PA, D'Agostino RB, Larson MG, Kannel WB, Benjamin EJ: A risk score for predicting stroke or death in individuals with new onset atrial fibrillation in the community: The Framingham Heart Study. JAMA 2003;290:10491056.

14 Gage BF, Waterman AD, Shannon W, Boechler M, Rich MW, Radford MJ: Validation of clinical classification schemes for predicting stroke: Results from the National Registry of atrial fibrillation. JAMA 2001;285:2864-2870.

15 Laupacis A, Albers G, Dalen G, Dunn MI, Jacobson AK, Singer DE: Antithrombotic therapy in atrial fibrillation. Chest 1998;114(suppl S):579S-589S.

16 The SPAFIII Writing Committee for Stroke Prevention in Atrial Fibrillation Investigators: Patients with nonvalvular atrial fibrillation at low risk of stroke during treatment with aspirin: Stroke prevention in atrial fibrillation III study. JAMA 1998;279:1273-1277.

17 Chugh SS, Blackshear JL, Shen WK, Hammill SC, Gersh BJ: Epidemiology and natural history of atrial fibrillation: Clinical implications. J Am Coll Cardiol 2001;37:371-378. 